\title{
CONCEPÇÕES DOCENTES SOBRE PRÁTICAS PEDAGÓGICAS INCLUSIVAS NA EDUCAÇÃO INFANTIL
}

\author{
Ana Paula Almeida Ferreira D1, Jackson Ronie Sá-Silva iD2, \\ Marcia Raika e Silva Lima ${ }^{3}$ e Maritania dos Santos Padilha 4
}

\section{Resumo}

O presente estudo teve como objetivo analisar, a partir de pesquisas científicas brasileiras, concepções docentes sobre práticas pedagógicas realizadas na educação infantil, tendo em vista o processo de inclusão das crianças, públicoalvo da educação especial (PAEE). Realizou-se uma revisão de literatura em artigos de revistas indexadas, disponibilizados no Portal de Periódicos da CAPES, Google Acadêmico e Scielo. Foram catalogados 10 artigos científicos referentes ao tema da pesquisa no período de 2016 a 2020. Como principais resultados, evidenciou-se a necessidade e urgência de estudos e debates acerca da inclusão de crianças PAEE, principalmente no que tange ao acesso à aprendizagem. Os resultados demonstram que os docentes têm concepções favoráveis à inclusão e empenham-se no desenvolvimento de práticas pedagógicas diversificadas com o propósito de contemplar a todos. Entretanto, verifica-se a necessidade de formação continuada na área, apoio da equipe escolar, recursos humanos e materiais para que o processo educativo de inclusão escolar ocorra de maneira satisfatória.

Palavras-chave: Educação Inclusiva; Educação Infantil; Crianças PAEE; Prática Pedagógica.

\section{TEACHERS' CONCEPTIONS OF INCLUSIVE PEDAGOGICAL PRACTICES IN EARLY CHILDHOOD EDUCATION}

\section{Abstract}

The present study aimed to analyze, based on Brazilian scientific research, teachers' conceptions about pedagogical practices in early childhood education, considering the process of inclusion of children, target population of special education (TPSE). A literature review was carried out on articles from indexed

\footnotetext{
${ }^{1}$ Mestranda em Educação Inclusiva em Rede (PROFEI) da Universidade Estadual do Maranhão (UEMA). Licenciada em Pedagogia pela UFMA. Professora da Rede Municipal de Educação de São Luís - MA (SEMED).

${ }^{2}$ Doutor em Educação pela UNISINOS; Pós-Doutor em Educação pela UFRGS; Professor do Programa de PósGraduação em Educação da Universidade Estadual do Maranhão (PPGE - Mestrado Profissional/UEMA) e do Mestrado Profissional em Educação Inclusiva em Rede (PROFEI) da Universidade Estadual do Maranhão (UEMA).

${ }^{3}$ Doutora em Educação pela Universidade Federal do Piauí (UFPI). Professora do Mestrado Profissional em Educação Inclusiva em Rede (PROFEI) da Universidade Estadual do Maranhão (UEMA).

${ }^{4}$ Mestranda em Educação Inclusiva em Rede (PROFEI) da Universidade Estadual do Maranhão (UEMA). Licenciada em Letras pela Universidade Metropolitana de Santos (UNIMES). Professora da Rede Estadual de Educação do Maranhão (SEDUC). 
journals, available at the CAPES Periodicals Portal, Google Scholar and Scielo. There were cataloged 10 scientific articles relating to the research theme in the period from 2016 to 2020. As main results, it became evident the need and urgency of studies and debates about the inclusion of SEN children, especially regarding the access to learning. The results show that teachers have favorable conceptions of inclusion and are committed to the development of diversified teaching practices with the purpose of including all children. However, there is a need for continued education in the area, support from the school team, human resources and materials so that the educational process of school inclusion may occur in a satisfactory manner.

Keywords: Inclusive Education; Early Childhood Education; TPSE Children; Pedagogical Practice.

\section{Introdução}

O Brasil, país signatário das declarações de Jomtien (1990) e Salamanca (1994) - documentos que universalizaram a educação inclusiva assegura em seu bojo legal a educação como direito de todos, visto que, a partir das orientações dos documentos internacionais citados, o país elabora suas próprias políticas de inclusão escolar para garantir direitos específicos às pessoas público-alvo da educação especial (PAEE).

Dessa maneira, é importante evidenciar uma considerável mudança no Brasil no que se refere às questões que envolvem o processo da inclusão escolar de alunos PAEE no início do século XXI, havendo na primeira década um avanço na criação de dispositivos e políticas "[...] em uma perspectiva de ampliação dos sujeitos a serem escolarizados no ensino comum" (BAPTISTA, 2013, p. 45).

O documento Política Nacional de Educação Especial na Perspectiva da Educação Inclusiva (BRASIL, 2008) contribuiu significativamente para a ampliação do acesso à inclusão escolar de alunos PAEE e para a criação de novos dispositivos legais na área da educação especial. De acordo com a Política, é considerado público-alvo da educação especial alunos que apresentam deficiências, transtornos globais do desenvolvimento e altas habilidades/superdotação.

De maneira mais específica, a Resolução no 04/2009 do Conselho Nacional de Educação que institui as Diretrizes Operacionais para o Atendimento Educacional Especializado na Educação Básica, determina que os alunos com deficiência são aqueles que apresentam algum impedimento físico, intelectual, mental ou sensorial de longo prazo. Por sua vez, os alunos com transtornos globais do desenvolvimento apresentam comprometimento no desenvolvimento neuropsicomotor, nas relações sociais e na comunicação. Encontra-se neste grupo alunos com autismo clássico, síndrome de Asperger, síndrome de Rett, transtorno desintegrativo da infância (psicoses) e transtornos invasivos sem outra especificação. Já os alunos com Altas habilidades/superdotação revelam uma grande potencialidade de 
conhecimento intelectual, psicomotor, criativo, artístico e liderança (BRASIL, 2009, Art. 4).

Com essa intensificação no que se refere à inclusão escolar de alunos PAEE, a sociedade, os órgãos governamentais e principalmente a escola, pela relação mais proximal com esse público, necessita ressignificar suas atitudes sociais e práticas pedagógicas tornando favorável o acesso, a permanência e a aprendizagem do alunado.

Importante considerar que a inclusão escolar é para além da socialização, instituindo-se como um dever a garantir o acesso ao currículo, devendo propor todo o suporte nesse processo de escolarização do aluno PAEE (MENDES, 2017), como a Política Nacional de Educação Especial na Perspectiva da Educação Inclusiva (BRASIL, 2008, p. 14) orienta os sistemas de ensino a garantir:

[...] acesso ao ensino regular, com participação, aprendizagem e continuidade nos níveis mais elevados do ensino; transversalidade da modalidade de educação especial desde a educação infantil até a educação superior; oferta do atendimento educacional especializado.

A discussão teórica deste trabalho se justifica por reconhecer que a área da educação infantil precisa pensar sobre a problematização da inclusão de crianças PAEE no ensino regular. Dessa maneira, compreende-se que as práticas pedagógicas traduzidas em atitudes sociais favoráveis à inclusão, estratégias e currículos diversificados poderão enriquecer significativamente o acesso, permanência e aprendizagem desse público.

Sendo a educação infantil início da vida escolar do sujeito, é também porta de entrada para a conscientização e a valorização da diversidade, entendendo a inclusão escolar dos alunos PAEE como um processo que precisa ser vivenciado o mais cedo possível. Dessa forma, as instituições precisam proporcionar ações que possibilitem atitudes de valorização e respeito às diferenças, oportunizando a todos o acesso ao conhecimento. Por tratar da relevância da inclusão escolar de crianças PAEE nas salas comuns, o estudo propôs investigar o seguinte questionamento: $O$ que revelam as pesquisas científicas acerca das práticas pedagógicas de docentes realizadas na Educação infantil em relação ao processo de inclusão de crianças PAEE?

Pretende-se através desta revisão, analisar a partir das pesquisas científicas brasileiras, concepções docentes sobre práticas pedagógicas realizadas na educação infantil, objetivando o processo de inclusão de crianças PAEE; descrever sobre práticas pedagógicas realizadas por professores da educação infantil com alunos PAEE; identificar as principais reflexões evidenciadas pelos pesquisadores sobre concepções docentes acerca das práticas no contexto da educação inclusiva, mostrando as perspectivas teóricometodológicas que fundamentaram estes trabalhos e as contribuições destas pesquisas. 
O artigo encontra-se estruturado em 5 seções: a primeira, apresenta-se a introdução com as descrições sobre a temática, justificativa, problemática, objetivos e organização da pesquisa. A segunda, trata sobre a educação especial na perspectiva da educação inclusiva contemplando crianças PAEE na educação infantil e os processos educativos no contexto escolar. A terceira, descreve o percurso metodológico utilizado para a realização da pesquisa e o quadro referente à revisão de literatura. A quarta, realiza a discussão e a análise dos resultados das pesquisas. E, por fim, as considerações finais.

\section{Educação Especial na Perspectiva da Educação Inclusiva}

Nesta seção serão abordados aspectos relevantes no que concerne à inclusão escolar, compreendendo a educação especial como modalidade que perpassa por todos os níveis, etapas e modalidade de ensino com ênfase no processo de inclusão de crianças PAEE na educação infantil. Posteriormente, serão levantados aspectos imprescindíveis sobre a inclusão no contexto escolar na busca pela garantia do acesso, da permanência, do desenvolvimento integral e da aprendizagem das crianças PAEE na escola da infância.

\subsection{A inclusão de crianças PAEE na educação infantil: institucionalização legal}

Nos últimos anos, o Brasil, assim como outros países, vem sendo destaque em relação à criação de dispositivos legais acerca da inclusão da pessoa PAEE, como tange a Constituição Federal de 1988, lei maior que rege o País, quando estabelece o direito de todos à educação em seu Art. 205:

A educação, direito de todos e dever do Estado e da família, será promovida e incentivada com a colaboração da sociedade, visando ao pleno desenvolvimento da pessoa, seu preparo para o exercício da cidadania (BRASIL, 1988, Art. 205).

O Estatuto da Criança e do Adolescente (ECA), afirma que é dever da família, da sociedade e do Estado assegurar a efetivação dos direitos referentes à educação, garantindo assim, o acesso e a permanência de todas as pessoas independentemente de suas especificidades e tipo de deficiência (BRASIL, 1990).

É importante frisar que a Lei Brasileira de Inclusão da Pessoa com Deficiência no 13.146, de 6 de julho de 2015 (Estatuto da Pessoa com Deficiência), em seu artigo $1^{\circ}$, se destina a: "[...] assegurar e a promover, em condições de igualdade, o exercício dos direitos e das liberdades fundamentais por pessoa com deficiência, visando à sua inclusão social e cidadania". Como se pode perceber em seu artigo $4^{\circ}$ que, "Toda pessoa com deficiência tem direito à igualdade de oportunidades com as demais pessoas e não sofrerá nenhuma espécie de discriminação" (BRASIL, 2015, Art. 4). 
A educação especial é uma modalidade de ensino que perpassa por todos os níveis e etapas do ensino, tendo seu início na educação infantil, na qual serão desenvolvidas capacidades para a construção da aprendizagem e desenvolvimento global. Nesse sentido, a Política Nacional de Educação Especial na Perspectiva da Educação Inclusiva (BRASIL, 2008, p. 16) no que se refere à educação infantil ressalta que,

[...] o lúdico, o acesso às formas diferenciadas de comunicação, a riqueza de estímulos nos aspectos físicos, emocionais, cognitivos, psicomotores, sociais e a convivência com as diferenças favorecem as relações interpessoais, o respeito e a valorização.

Desse modo, entende-se que quanto mais cedo ocorrerem interações entre todas as crianças mais se oportuniza o acesso, o desenvolvimento e a aprendizagem para todos, assim, há maior probabilidade no êxito à inclusão tanto na esfera educacional quanto social.

Por ser um espaço de socialização e de aprendizagem para a inclusão na educação infantil, as instituições de ensino devem proporcionar interações dos sujeitos com seus pares no intuito de facilitar uma educação que respeite as diferenças baseada na concepção de inclusão.

É importante ressaltar que o direito da criança à educação está garantido tanto na Constituição de 1988 (BRASIL, 1988) quanto na Lei de Diretrizes e Bases da Educação Nacional (LDB), no 9.394/96, em que se legitima a inclusão de instituições da educação infantil nas redes de ensino. A primeira estabelece que 0 acesso à educação infantil deva ser em creches e pré-escola, até os 5 anos de idade (BRASIL, 1988). Já a LDB no 9.394/96 específica a função das instituições infantis e define a educação infantil como:

[...] primeira etapa da educação básica, tem como finalidade o desenvolvimento integral da criança de até 5 (cinco) anos, em seus aspectos físico, psicológico, intelectual e social, complementando a ação da família e da comunidade (BRASIL, 1996, Art. 29).

$\mathrm{Na}$ escola infantil, encontramos diversos tipos de relações interpessoais indispensáveis para o desenvolvimento e a aprendizagem da criança. 0 contato entre pares, com diferentes valores, atitudes e costumes, contribui para a aprendizagem de todas as crianças e também na eliminação de algum tipo de preconceito e discriminação. Mendes (2010, p. 58) esclarece que:

Ambientes inclusivos podem favorecer o desenvolvimento das crianças por oferecer um meio mais estimulador (cognitivamente, socialmente e linguisticamente) do que ambientes segregados. [...] com suporte necessário e apropriado, as crianças pequenas com necessidades educacionais especiais podem adquirir habilidades complexas e participar com sucesso de ambientes inclusivos. 
Portanto, fica evidente que o processo de inclusão escolar precisa urgentemente beneficiar todos os alunos, pois é importante criar mecanismos que possibilitem a convivência destes, logo nos primeiros anos de vida, no intuito de enriquecer as relações humanas e desenvolver o respeito mútuo. Como é observado por Abdalla (2016, p. 87) o ambiente escolar deve ser um espaço:

[...] em que as diferenças no sentido de discriminação sejam minimizadas e a inclusão de pessoas com deficiências ocorra de forma natural. Procurar trabalhar para promover no outro seja deficiente ou não, a busca pelas suas capacidades e superação de suas dificuldades.

Entretanto, percebe-se que têm muito a ser feito para que haja a inclusão escolar de alunos PAEE, pois apesar de todo amparo legal, nota-se a necessidade de reorganização do sistema para que a inclusão escolar contemple a todos de maneira eficaz. Considerando que apenas a matrícula não garante o sucesso à inclusão, Smelter, Rasch e Yudewitz (1994, p. 35 apud MENDES, 2017, p. 73) descrevem a inclusão escolar como a prática de "[...] inserir os estudantes da educação especial nas classes comuns do ensino regular, levando com elas os suportes que precisam, mais do que as tirando para os serviços de apoio".

É importante frisar que todas as possibilidades devem refletir no processo de inclusão para garantir: matrícula, permanência, socialização, acesso ao currículo, materiais e recursos adaptados. Assim, os professores da sala regular juntamente com outros profissionais (professores especialistas na educação especial, coordenador pedagógico, gestor e outros) envolvidos no processo de inclusão devem construir juntos propostas educativas na perspectiva de valorização à diversidade e particularidade de cada aluno.

\subsection{A inclusão no contexto escolar}

A proposta de inclusão escolar passou a ser temática de muita discussão nas últimas décadas, especialmente no que se refere aos desafios encontrados no processo de aprendizagem dos alunos PAEE. Santiago e Santos (2015, p. 497) ressaltam que "[...] a inclusão requer quebras de cristalizações educacionais e reorganização do sistema educacional para que se efetivem ambientes dinâmicos e envolventes para estimular todos os alunos". Por causa disso, é necessário uma ressignificação de todos os aspectos que contribuem para o acesso, participação e aprendizagem dos alunos PAEE voltadas para a perspectiva de "[...] igualdade de condições para o acesso e permanência na escola de todos". Garantindo "[...] a universalidade e a equidade para todos os cidadãos na rede regular de ensino" (HEREDERO, 2010, p. 195).

Deve-se considerar a sala de aula inclusiva como um espaço propício para aprendizagem, tornando-se necessário a utilização de práticas pedagógicas que atendam às especificidades e as possibilidades dos alunos. 
Desse modo, Vílchez (2018, p. 18) defende que esse ambiente deve contemplar:

[...] uma diversidade de práticas didáticas, com aprendizagens diferenciadas e materiais adaptados, que potencializem as habilidades dos estudantes com deficiência e conteúdos que estejam acordo com suas experiências.

No que se refere à necessidade de práticas pedagógicas diversificadas para a inclusão escolar de alunos PAEE, é pertinente considerar a importância da conscientização, ressignificação e valorização da diversidade humana, mas para isso o professor precisa estar aberto a novas aprendizagens que eliminem ações educativas homogeneizadoras. Diante disso, o professor regente da sala regular precisa criar novas estratégias de ensino para desenvolver as habilidades e as competências necessárias para que todos os alunos tenham acesso ao currículo escolar.

Nesse contexto, a escola tem um grande papel no processo de inclusão, pois é indispensável que gestores, coordenadores e toda comunidade escolar acompanhem e apoiem esse processo, pois os alunos não são apenas responsabilidades dos professores, e sim de todos da escola. De acordo com Saracho (2016 apud VÍLCHEZ, 2018, p. 22-23):

O reconhecimento da inclusão deve estar distante das experiências e dos diferentes tipos de discriminação (físico, social e psicológico), os quais devem ser controlados e supervisionados pelos diferentes atores da escola [...], tanto quanto a sua prevenção, como quanto a gerar mecanismos de sanção para seus instigadores e opressores.

Outra ação relevante, que contribuirá significativamente na mudança de atitudes e em práticas pedagógicas escolares inclusivas, corresponde à formação docente na área. Souza, Pereira e Lindolpho (2018) destacam pesquisas que apontam mudanças de ações favoráveis à inclusão escolar de professores que realizaram cursos e/ou formações na área. Essa afirmação é ratificada pelos autores, quando concluem em seu estudo, que a formação é uma engrenagem que permite transformações nos pensamentos e nas atitudes sociais dos professores. Logo, é pertinente compreender que:

O professor inclusivo é aquele que compreende as diferenças do outro, que não tem preconceito, que se compromete e que busca conhecimento para poder efetivar o processo inclusivo (ABDALLA, 2016, p. 25-26).

Observa-se a necessidade da parceria constante entre os professores da sala regular e do professor do Atendimento Educacional Especializado - AEE, tendo em vista que este profissional deve articular-se com os demais professores da classe comum para orientá-los e, em conjunto, propor possibilidades de aprendizagens enriquecedoras. Também se faz necessário, (c)(1) $(8)$ 
que o professor do AEE identifique, produza e utilize recursos que favoreçam o acesso do aluno ao currículo escolar. Nesse caso, o uso das tecnologias assistivas seria ideal para essa situação, pois correspondem a produtos, recursos, metodologias, estratégias, práticas e serviços que permitem que as pessoas com deficiência potencializem suas forças e demonstrem suas habilidades (SOMOS EDUCAÇÃO, 2020).

O planejamento coletivo (professores da sala regular, do AEE e o coordenador) é outro elemento fundamental para socializar experiências e buscar novas alternativas favoráveis ao processo de ensino-aprendizagem. Como destaca Vagula (2011, p. 117) o planejamento é um importante elemento articulador da prática pedagógica, pois:

A reflexão sobre a organização do trabalho pedagógico na escola é uma necessidade emergente, uma vez que planejar contribui para a eficácia do processo de ensino e aprendizagem e possibilita resgatar a intencionalidade da ação.

Desta forma, é necessário a escola incorporar em suas metas e objetivos educacionais a proposta de inclusão, que contemple não apenas o direito à matricula e à participação nas relações sociais, mas também, a garantia de permanência e aprendizagem aos alunos. Assim, é importante que a escola assegure formação aos professores, disponibilize horários para planejamentos coletivos, contemple proposta de trabalho colaborativo, além de auxiliar nas estratégias, materiais, recursos e atividades diversificadas que favoreçam uma aprendizagem significativa a todos os alunos.

\section{Metodologia}

Realizou-se uma revisão de literatura de artigos científicos buscando conhecer e compilar informações sobre as concepções docentes acerca das práticas pedagógicas realizadas na educação infantil no processo de inclusão de crianças PAEE.

O estudo constitui-se numa abordagem qualitativa de caráter bibliográfico, por entender que este tipo de pesquisa permite "[...] ao investigador a cobertura de uma gama de fenômenos muito mais amplo do que aquela que poderia pesquisar diretamente" (GIL, 2002, p. 45). Desse modo, a pesquisa bibliográfica possibilita acesso a um leque de publicações científicas relacionado ao objeto do estudo em pauta.

Utilizou-se como critérios para o levantamento bibliográfico dos artigos os seguintes descritores: inclusão, educação inclusiva, educação infantil, prática pedagógica, concepção, trabalho pedagógico, docente, deficiência e público-alvo da educação especial. No decorrer das pesquisas foram avaliados e selecionados estudos que revelassem no título e/ou no resumo o objeto proposto, publicados entre os anos de 2016 a 2020. Ao fim das buscas foi selecionado um total de 10 artigos encontrados nos portais Periódicos CAPES, Google acadêmico e Scielo. 
Segue abaixo o Quadro 1 com a apresentação dos artigos, bem como seus títulos, autores, ano de publicação, objetivos, metodologias e resultados a partir da busca realizada no campo educacional sobre inclusão de crianças PAEE na educação infantil.

Quadro 1 - Apresentação dos artigos selecionados e analisados.

\begin{tabular}{|c|c|c|c|c|}
\hline & Artigo & Objetivo & Metodologia & Resultados \\
\hline 1 & $\begin{array}{lr}\text { Título: } & \\
\text { O } & \text { TRABALHO } \\
\text { PEDAGÓGICO PARA } \\
\text { ALUNOS PÚBLICO- } \\
\text { ALVO } \\
\text { EDUCAÇÃO } \\
\text { ESPECIAL: } \\
\text { INVESTIGANDO A } \\
\text { INCLUSÃO } \\
\text { EDUCAÇÃO } \\
\text { INFANTIL } \\
\text { Autoras: Fachinetti; } \\
\text { Nascimento } \\
\text { Giroto, 2016. }\end{array}$ & $\begin{array}{l}\text { Investigar } \\
\text { como se dá o } \\
\text { trabalho } \\
\text { pedagógico } \\
\text { desse } \\
\text { professor, } \\
\text { em classe } \\
\text { regular, na } \\
\text { educação } \\
\text { infantil, para } \\
\text { alunos } \\
\text { público-alvo } \\
\text { da educação } \\
\text { especial, com } \\
\text { vistas à } \\
\text { apropriação } \\
\text { do curŕculo, } \\
\text { por parte } \\
\text { desse público. }\end{array}$ & $\begin{array}{l}\text { Abordagem } \\
\text { qualitativa. } 4 \\
\text { professoras } \\
\text { participantes } \\
\text { da pesquisa. } \\
\text { Coleta de } \\
\text { dados ocorreu } \\
\text { por meio de } \\
\text { um roteiro de } \\
\text { observação. A } \\
\text { análise de } \\
\text { dados se deu } \\
\text { por meio da } \\
\text { elaboração de } \\
\text { categorias. }\end{array}$ & $\begin{array}{l}\text { Os dados revelam a inclusão dos } \\
\text { alanos nas atividades } \\
\text { desenvolvidas e de que modo as } \\
\text { professoras utilizavam sua } \\
\text { prática docente para atender a } \\
\text { todos os alunos e, } \\
\text { particularmente, aos que se } \\
\text { encontravam caracterizados } \\
\text { como público-alvo da educação } \\
\text { especial. Também é evidenciou- } \\
\text { se a importância de adaptações } \\
\text { metodológicas e reflexão sobre } \\
\text { as práticas pedagógicas } \\
\text { inclusivas nessa etapa do do } \\
\text { processo de escolarização desse } \\
\text { público. }\end{array}$ \\
\hline 2 & $\begin{array}{l}\text { Título: } \\
\text { TRABALHO } \\
\text { DOCENTEr COM } \\
\text { ALUNOS PÚBLICO- } \\
\text { ALVO } \\
\text { EDUCAÇÃO } \\
\text { ESPECIAL } \\
\text { EDUCAÇÃO } \\
\text { INFANTIL } \\
\text { Autoras: Marques e } \\
\text { Giroto, 2016. }\end{array}$ & $\begin{array}{l}\text { Analisar o } \\
\text { trabalho } \\
\text { docente, na } \\
\text { educação } \\
\text { infantil, com } \\
\text { alunos } \\
\text { Público-Alvo } \\
\text { da educação } \\
\text { especial } \\
\text { (PAEE), em } \\
\text { sala de aula } \\
\text { comum, } \\
\text { particularme } \\
\text { nte no que } \\
\text { se refere a } \\
\text { alunos com } \\
\text { transtorno do } \\
\text { espectro } \\
\text { autista. }\end{array}$ & $\begin{array}{l}\text { Estudo de } \\
\text { caso com } \\
\text { abordagem } \\
\text { qualitativa } \\
\text { com a } \\
\text { participação } \\
\text { de uma } \\
\text { docente da } \\
\text { educação } \\
\text { infantil. } \\
\text { Instrumento } \\
\text { de coleta de } \\
\text { dados foi a } \\
\text { entrevista } \\
\text { semiestrutura } \\
\text { da. }\end{array}$ & $\begin{array}{l}\text { Ficou evidente que o papel do } \\
\text { professor da educação infanti } \\
\text { no processo de escolarização de } \\
\text { alunos PAEE assume relevância, } \\
\text { não apenas no que se refere à } \\
\text { questão atitudinal, mas também } \\
\text { no que diz respeito às práticas } \\
\text { pedagógicas com esses alunos, } \\
\text { em sala de aula. } \\
\text { A precarização da formação } \\
\text { docente e infraestrutura. }\end{array}$ \\
\hline 3 & $\begin{array}{lr}\text { Título: } & \text { EDUCAÇÃO } \\
\text { INCLUSIVA: } & \text { UM } \\
\text { ESTUDO DE } & \text { CASO } \\
\text { SOBRE } & \\
\end{array}$ & $\begin{array}{l}\text { Verificar } \\
\text { como se dá o } \\
\text { trabalho } \\
\text { pedagógico }\end{array}$ & $\begin{array}{l}\text { Pesquisa de } \\
\text { estudo de } \\
\text { caso com } \\
\text { abordagem } \\
\end{array}$ & $\begin{array}{l}\text { O estudo demonstrou ocorrência } \\
\text { de uma prática pedagógica } \\
\text { significativa em relação à a } \\
\text { inclusão e preocupação com }\end{array}$ \\
\hline
\end{tabular}




\begin{tabular}{|c|c|c|c|c|}
\hline & $\begin{array}{l}\text { TRABALHO } \\
\text { DOCENTE NA } \\
\text { EDUCAÇÃO } \\
\text { INFANTIL } \\
\text { Autoras: Batista e } \\
\text { Manzoli, 2016. }\end{array}$ & $\begin{array}{l}\text { com alunos } \\
\text { PAEE em } \\
\text { uma sala de } \\
\text { aula comum } \\
\text { na educação } \\
\text { infantil. }\end{array}$ & $\begin{array}{l}\text { qualitativa. } \\
\text { Participou da } \\
\text { pesquisa uma } \\
\text { professora do } \\
\text { ensino regular } \\
\text { da educação } \\
\text { infantil. } \\
\text { Instrumento } \\
\text { de coleta de } \\
\text { dados foi a } \\
\text { entrevista } \\
\text { semiestrutura } \\
\text { da. }\end{array}$ & $\begin{array}{l}\text { desenvolvimento. } \\
\text { Os resultados apresentaram que } \\
\text { se faz necessário uma maior } \\
\text { colaboração entre os } \\
\text { profissionais da escola e maior } \\
\text { participação por parte da } \\
\text { família, para que a educação } \\
\text { inclusiva seja verdadeiramente } \\
\text { realizada. }\end{array}$ \\
\hline & $\begin{array}{l}\text { Título: } \\
\text { O ENSINO } \\
\text { COLABORATIVO } \\
\text { COMO } \\
\text { FACILITADOR DA } \\
\text { EDUCAÇÃO } \\
\text { INCLUSIVA } \\
\text { EDUCAÇÃO } \\
\text { INFANTIL } \\
\text { Autoras: Mendes e } \\
\text { Galvani, 2017. }\end{array}$ & $\begin{array}{ll}\begin{array}{l}\text { Descrever } \\
\text { analisar }\end{array} & \text { o } \\
\text { processo de } & \text { dma } \\
\text { untervenção } \\
\text { intre } & \text { o } \\
\text { entre } & \\
\text { professor de } & \\
\text { educação } & \\
\text { infantil da } \\
\text { classe } \\
\text { comum e o } \\
\text { professor de } \\
\text { educação } \\
\text { especial com } \\
\text { vistas } \\
\text { formação } \\
\text { baseada no } \\
\text { ensino } \\
\text { colaborativo } \\
\text { e adaptação } \\
\text { de } \\
\text { atividades. }\end{array}$ & $\begin{array}{l}\text { Pesquisa } \\
\text { colaborativa } \\
\text { com análise } \\
\text { qualitativa, } \\
\text { com foco no } \\
\text { trabalho de } \\
\text { duas } \\
\text { professoras. } \\
\text { Os } \\
\text { instrumentos } \\
\text { de coletas de } \\
\text { dados foram: } \\
\text { diário de } \\
\text { campo da } \\
\text { pesquisadora; } \\
\text { protocolo de } \\
\text { registro do } \\
\text { planejamento } \\
\text { das reuniões } \\
\text { com as as } \\
\text { professoras e } \\
\text { roteiro de } \\
\text { observação. }\end{array}$ & $\begin{array}{l}\text { Os dados revelam que as } \\
\text { professoras perceberam o } \\
\text { ensino colaborativo como algo } \\
\text { positivo que contribuiu } \\
\text { significativamente para a } \\
\text { superação dos desafios } \\
\text { inerentes à prática pedagógica } \\
\text { com a criança com síndrome de } \\
\text { Down e apontaram o ensino } \\
\text { colaborativo como uma } \\
\text { estratégia facilitadora na } \\
\text { educação infantil. } \\
\text { O ensino colaborativo necessita } \\
\text { de legislação que regulamente } \\
\text { seu funcionamento e promova } \\
\text { maior difusão do serviço para } \\
\text { outros locais. }\end{array}$ \\
\hline 5 & $\begin{array}{l}\text { Título: INCLUSÃO } \\
\text { NA EDUCAÇÃO } \\
\text { INFANTIL: } \\
\text { DESAFIOS } \\
\text { POSSIBILIDADES } \\
\text { ATRAVÉS DAS } \\
\text { PRÁTICAS } \\
\text { PEDAGÓGICAS } \\
\text { Autoras: Santos e } \\
\text { Almeida, 2017. }\end{array}$ & $\begin{array}{l}\text { Levantar } \\
\text { uma } \\
\text { discussão } \\
\text { acerca do } \\
\text { processo de } \\
\text { inclusão na } \\
\text { educação } \\
\text { infantil } \\
\text { através das } \\
\text { práticas } \\
\text { pedagógicas. }\end{array}$ & $\begin{array}{l}\text { Pesquisa } \\
\text { bibliográfica } \\
\text { com análise } \\
\text { reflexiva } \\
\text { sobre a } \\
\text { inclusão nas } \\
\text { escolas } \\
\text { regulares de } \\
\text { educação } \\
\text { infantil, do } \\
\text { através diálogo entre } \\
\text { teoria } \\
\text { práticas e } \\
\text { pedagógicas. }\end{array}$ & $\begin{array}{l}\text { Conclui-se que as escolas } \\
\text { precisam possibilitar } \\
\text { experiências significativas que } \\
\text { levem as crianças a } \\
\text { desenvolverem suas habilidades } \\
\text { e possam construir seus } \\
\text { conhecimentos considerando as } \\
\text { especificidades e potencialidades } \\
\text { de cada um. Evidencia-se a } \\
\text { necessidade de formação } \\
\text { continuada e prática pedagógica } \\
\text { crítico-reflexiva. }\end{array}$ \\
\hline 6 & $\begin{array}{lr}\text { Título: } & \text { INCLUSÃO } \\
\text { DAS } & \text { CRIANÇAS }\end{array}$ & $\begin{array}{lr}\text { Discutir } & \text { a } \\
\text { inclusão } & \text { das }\end{array}$ & $\begin{array}{l}\text { Pesquisa } \\
\text { teórica com }\end{array}$ & $\begin{array}{l}\text { Constatou-se que a realidade } \\
\text { contemporânea nos mostra que }\end{array}$ \\
\hline
\end{tabular}




\begin{tabular}{|c|c|c|c|c|}
\hline & $\begin{array}{l}\text { COM DEFICIÊNCIA } \\
\text { NA } \quad \text { EDUCAÇÃO } \\
\text { INFANTIL: } \\
\text { PROCESSO EM } \\
\text { CONSTRUÇÃO } \\
\text { Autor: Alves, } 2018 .\end{array}$ & $\begin{array}{l}\text { crianças com } \\
\text { deficiência na } \\
\text { educação } \\
\text { infantil, } \\
\text { ressaltando } \\
\text { as práticas e } \\
\text { os desafios } \\
\text { deste } \\
\text { processo em } \\
\text { construção. }\end{array}$ & $\begin{array}{lr}\text { ênfase } & \text { na } \\
\text { concepção de } \\
\text { infância, } \\
\text { criança com } \\
\text { deficiência, } \\
\text { educação } \\
\text { infantil no } \\
\text { Brasil e a } \\
\text { criança com } \\
\text { deficiência na } \\
\text { educação } \\
\text { infantil. }\end{array}$ & $\begin{array}{l}\text { as concepções e práticas } \\
\text { padronizadas } \\
\text { homogeneizantes não permitem } \\
\text { abordarmos as diferenças que } \\
\text { pulsam contundentemente nos } \\
\text { ambientes educacionais e estas } \\
\text { não devem ser mais tratadas } \\
\text { como manifestações invisíveis } \\
\text { ou expressões que devemos } \\
\text { neutralizar ou anular. }\end{array}$ \\
\hline & $\begin{array}{lr}\text { Título: } & \\
\text { EDUCAÇÃO } & \\
\text { ESPECIAL } & \text { DOS } \\
\text { SURDOS: O } & \text { QUE } \\
\text { DIZEM } & \text { OS } \\
\text { DOCENTES } & \text { EM UMA } \\
\text { ESCOLA } & \text { DE } \\
\text { EDUCAÇÃO } & \\
\text { INFANTIL } & \text { NO } \\
\text { MUNICÍPIO } & \text { DE } \\
\text { ITAPIPOCA/CE } & \\
\text { Autores: } & \text { Sousa; } \\
\text { Silva e Lima, } & \text { 2019. }\end{array}$ & $\begin{array}{l}\text { Analisar as } \\
\text { concepções } \\
\text { dos docentes } \\
\text { sobre a } \\
\text { inclusão de } \\
\text { alunos } \\
\text { surdos em } \\
\text { uma escola } \\
\text { pública de } \\
\text { educação } \\
\text { infantil no } \\
\text { município de } \\
\text { Itapipoca/CE. }\end{array}$ & $\begin{array}{l}\text { Pesquisa de } \\
\text { campo com } \\
\text { abordagem } \\
\text { qualitativa de } \\
\text { caráter } \\
\text { descritivo. } \\
\text { Instrumento } \\
\text { de coleta de } \\
\text { dados } \\
\text { questionários } \\
\text { com } 5 \\
\text { professores } \\
\text { participantes. } \\
\text { Para } \\
\text { discussão e } \\
\text { análise } \\
\text { utilizou-se a } \\
\text { análise de } \\
\text { conteúdo. }\end{array}$ & 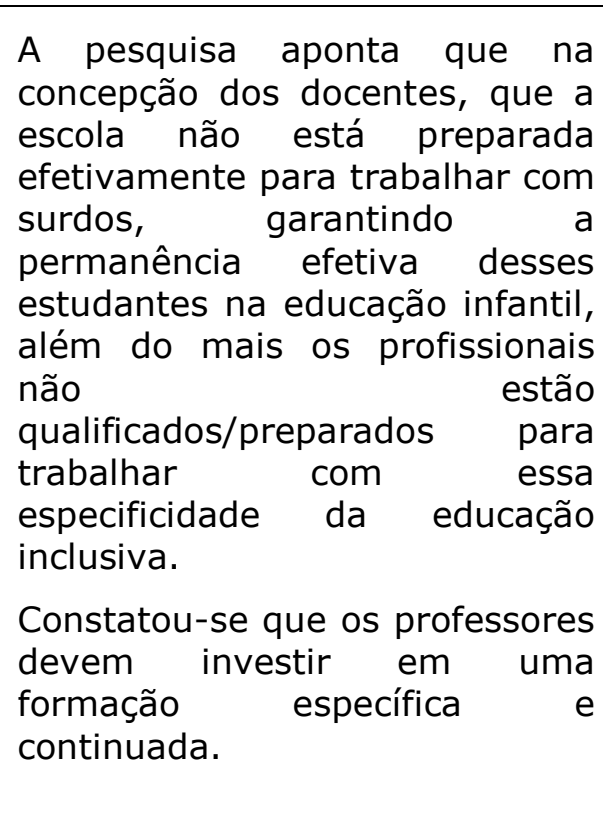 \\
\hline 8 & \begin{tabular}{lr} 
Título: \\
O PROFESSOR E A \\
INCLUSÃO & DE \\
CRIANÇAS & COM \\
TRANSTORNO & DO \\
ESPECTRO AUTISTA \\
$-\quad$ TEA NAS SALAS \\
DE $\quad$ EDUCAÇÃO \\
INFANTIL \\
MUNICÍPIO DO \\
ARAPIRACA - AL \\
\multicolumn{2}{l}{ Autores: Magalhães } \\
e Acioli, 2020.
\end{tabular} & $\begin{array}{l}\text { Analisar a } \\
\text { inclusão de } \\
\text { crianças com } \\
\text { TEA nos } \\
\text { Centros de } \\
\text { educação } \\
\text { infantil no } \\
\text { município de } \\
\text { Arapiraca - } \\
\text { AL, } \\
\text { considerando } \\
\text { a relação } \\
\text { entre a teoria } \\
\text { e à prática } \\
\text { pedagógica. }\end{array}$ & $\begin{array}{l}\text { Pesquisa } \\
\text { bibliográfica e } \\
\text { de campo. } \\
\text { Instrumento } \\
\text { de coleta de } \\
\text { dados foi } \\
\text { entrevistas } \\
\text { semiestrutura } \\
\text { das realizadas } \\
\text { com as quatro } \\
\text { professoras } \\
\text { de crianças } \\
\text { com TEA. } \\
\text { Para analise, } \\
\text { as entrevistas } \\
\text { foram } \\
\text { analisadas e } \\
\text { separadas por } \\
\text { categorias. }\end{array}$ & $\begin{array}{l}\text { Contatou-se na pesquisa que } \\
\text { apesar dos professores não } \\
\text { apresentarem formações } \\
\text { acadêmicas especificas, falta de } \\
\text { experiência e pouco } \\
\text { conhecimento sobre o assunto, } \\
\text { os mesmos demostram } \\
\text { interesses em contribuir na } \\
\text { aprendizagem da criança } \\
\text { autista. A pesquisa também } \\
\text { evidencia falta de formação, } \\
\text { apoio pedagógico, material e } \\
\text { pessoal aos professores. }\end{array}$ \\
\hline 9 & $\begin{array}{l}\text { Título: } \\
\text { A } \quad \text { EDUCAÇÃO } \\
\text { ESPECIAL PARA }\end{array}$ & $\begin{array}{l}\text { Compreender } \\
\text { como } \\
\text { profissionais }\end{array}$ & $\begin{array}{lr}\text { Pesquisa } & \text { de } \\
\text { estudo } & \text { de } \\
\text { caso e como }\end{array}$ & $\begin{array}{l}\text { Os resultados apontam que, } \\
\text { embora façam referência à } \\
\text { criança como sujeito de direitos }\end{array}$ \\
\hline
\end{tabular}




\begin{tabular}{|c|c|c|c|c|}
\hline & $\begin{array}{l}\text { CRIANÇAS DE ZERO } \\
\text { A TRÊS ANOS: } \\
\text { PERSPECTIVAS E } \\
\text { PRÁTICAS DE } \\
\text { PROFISSIONAIS DA } \\
\text { EDUCAÇÃO } \\
\text { INFANTIL } \\
\text { Autora: Mascena, } \\
2020 .\end{array}$ & $\begin{array}{l}\text { que atuam } \\
\text { com crianças } \\
\text { de zero a } \\
\text { três anos e } \\
\text { que são o } \\
\text { público-alvo } \\
\text { da educação } \\
\text { especial em } \\
\text { um centro } \\
\text { municipal de } \\
\text { educação } \\
\text { infantil do } \\
\text { município de } \\
\text { Vitória } \\
\text { concebem a } \\
\text { prática } \\
\text { educativa } \\
\text { destinada a } \\
\text { essas } \\
\text { crianças. }\end{array}$ & $\begin{array}{l}\text { instrumento } \\
\text { de coleta de } \\
\text { dados utilizou } \\
\text { entrevistas, } \\
\text { questionários } \\
\text { e análise } \\
\text { documentos. } \\
\text { Os participantes } \\
\text { da pesquisa } \\
\text { foram } 14 \\
\text { profissionais } \\
\text { que atuam } \\
\text { diretamente } \\
\text { com crianças } \\
\text { de zero a três } \\
\text { anos PAEE. }\end{array}$ & $\begin{array}{l}\text { e reconheçam que a educação } \\
\text { infantil é direito de todas as } \\
\text { crianças, incluindo as que } \\
\text { apresentam indicativo à } \\
\text { educação especial, algumas } \\
\text { profissionais ainda têm dúvidas } \\
\text { e receios em relação ao trabalho } \\
\text { direcionado a essas crianças. Os } \\
\text { profissionais investigados } \\
\text { sinalizam o investimento no } \\
\text { trabalho colaborativo e na } \\
\text { formação continuada; a } \\
\text { disponibilização de um maior } \\
\text { número de profissionais } \\
\text { especializados para apoio à } \\
\text { inclusão. }\end{array}$ \\
\hline 10 & $\begin{array}{l}\text { Título: } \\
\text { EDUCAÇÃO } \\
\text { INFANTIL: } \\
\text { MÉTODOS E } \\
\text { ESTRATÉGIAS PARA } \\
\text { INCLUSÃO } \\
\text { Autores: Melo e } \\
\text { Coutinho, 2020. }\end{array}$ & $\begin{array}{l}\text { Analisar } \\
\text { como está } \\
\text { sendo } \\
\text { utilizadas as } \\
\text { metodologias } \\
\text { e estratégias } \\
\text { desenvolvida } \\
\text { s nas turmas } \\
\text { de educação } \\
\text { infantil pelos } \\
\text { docentes da } \\
\text { Escola João } \\
\text { Duarte da } \\
\text { Vila r de } \\
\text { Ameixas }- \\
\text { PE. }\end{array}$ & $\begin{array}{l}\text { Pesquisa de } \\
\text { estudo de } \\
\text { caso com } \\
\text { abordagem } \\
\text { qualitativa } \\
\text { realizada com } \\
2 \text { professores } \\
\text { da educação } \\
\text { infantil em } \\
\text { uma escola de } \\
\text { Pernambuco, } \\
\text { Nordeste do } \\
\text { Brasil. O } \\
\text { instrumento } \\
\text { de coleta de } \\
\text { dados foi o } \\
\text { questionário. }\end{array}$ & $\begin{array}{l}\text { Verifica-se como as professoras } \\
\text { estão conseguindo desenvolver } \\
\text { seu trabalho pedagógico com } \\
\text { alunos incluídos na sala de aula } \\
\text { regular, sendo possível observar } \\
\text { o quanto a formação docente. O } \\
\text { brincar o brincar é visto como } \\
\text { uma estratégia essencial para } \\
\text { incluir a criança com deficiência. } \\
\text { É evidenciada a necessidade de } \\
\text { apoio pedagógico e consolidação } \\
\text { da parceria entre escola e } \\
\text { família. }\end{array}$ \\
\hline
\end{tabular}

Fonte: Elaborado pelos autores (2021).

\section{Resultados e discussões}

Tendo como base as leituras dos artigos científicos selecionados, esta seção dispõe discussão e análise sobre os aspectos mais evidenciados e problematizados pelos estudos no que tange às concepções de docentes sobre práticas pedagógicas inclusivas de crianças PAEE nas salas regulares da educação infantil. Também foram enfatizadas as contribuições das pesquisas sobre o objeto do estudo.

Verificou-se a unanimidade nos estudos aplicados de Fachinetti, Nascimento e Giroto (2016), Marques e Giroto (2016), Batista e Manzoli (2016), Mendes e Galvani (2017), Sousa, Silva e Lima (2019), Magalhães e Acioli (2020), Mascena (2020) e Melo e Coutinho (2020) o reconhecimento e 
atitudes favoráveis à inclusão de crianças PAEE na educação infantil, uma vez que os professores participantes acreditam que o contato entre pares desde a tenra idade, contribui para que as diferenças sejam um aspecto positivo para valorizar as particularidades e potencialidades de cada um. Entretanto, em alguns casos como no estudo de Mascena (2020, p. 123) nota-se:

[...] uma tendência a considerar que apenas a socialização seja tratada com centralidade nas práticas da educação infantil direcionada à criança de zero a três anos que é público-alvo da educação especial. Essa ênfase pode ser entendida como uma pista de que a política de educação inclusiva não tem sido colocada em prática.

Nesse contexto, é importante considerar que a inclusão escolar não corresponde apenas ao acesso e à participação nas interações sociais, mas também requer a garantia do direito à aprendizagem de todos. Como ressalta Abdalla (2016, p. 90),

[...] a inclusão escolar não significa inserir o aluno com deficiência junto dos outros num mesmo ambiente. Implica em proporcionar a participação do estudante nas atividades realizadas e oportunizar o uso dos materiais da escola que são para todos os alunos.

As pesquisas bibliográficas realizadas por Santos e Almeida (2017) e Alves (2018) enfatizam, que na contemporaneidade, as concepções de práticas pedagógicas padronizadas não permitem potencializar o desenvolvimento das habilidades para a construção dos conhecimentos, considerando as especificidades e as potencialidades de cada aluno. Dessa maneira, a realidade mostra que muitos entraves têm sido enfrentados na tentativa de pôr em prática as determinações legais, a começar pela escola que na maioria das vezes não está apta a receber alunos PAEE, tanto no âmbito físico como pedagógico. Assim, para que haja de fato a inclusão, será necessário, entre outros aspectos, "[...] a reorganização do cotidiano e a ressignificação da cultura escolar" (PLETSCH; GLAT, 2013, p. 19).

Apesar de serem identificados pelos autores o medo, as incertezas e a insegurança no processo de inclusão, destacam que os professores participantes, de acordo com a análise dos autores, são conscientes sobre o direito da educação a todos, bem como têm a compreensão de que a inclusão das crianças PAEE na educação infantil contribui significativamente no desenvolvimento, na aprendizagem, além de favorecer o enriquecimento da valorização e do respeito à diversidade.

Os autores consideram, a partir das análises das pesquisas, que os professores buscam contemplar em suas práticas pedagógicas metodologias e estratégias que possibilitem um currículo flexível atendendo à todas as necessidades dos seus alunos. Nesse âmbito, observa-se a compreensão de que a proposta inclusiva implica em tomadas de estratégias importantes como 
as adaptações curriculares, que proporcionem caminhos para que os alunos aprendam os conhecimentos que estão sendo socializados na sala regular. Conforme destaca Heredero (2010, p. 200) as adaptações curriculares constituem:

[...] possibilidades educacionais de atuar frente às dificuldades de aprendizagem dos alunos [...]. Não é um novo currículo, mas sim um currículo dinâmico, alterável, passível de ampliação, para que atenda realmente a todos os educandos.

Entretanto, apesar do empenho dos professores em efetivar a inclusão, é percebido pelos autores algumas dificuldades encontradas na realização de práticas pedagógicas diversificadas, o que implica na necessidade de formação continuada dos professores, uma vez que esta proporciona a construção do conhecimento teórico, além de trocas de experiências e reflexão sobre as ações educativas. Como enfatizam os estudos de Magalhães e Acioli (2020, p. 22) cabe "[...] aos ambientes educativos promover e estimular os professores a participarem de constantes processos de formação continuada voltadas a discussão sobre a inclusão escolar". A ausência de momentos de trocas de experiências e de formação dos professores do ensino regular dificulta significativamente para que a factual inclusão aconteça como prevista nos dispositivos legais (VILARONGA; MENDES, 2014).

Nesse cenário, faz-se necessário também propor formação inicial para o professor inclusivo com disciplinas e estágio, colocando-o em situações de sala de aula, e é importante disseminar esta temática para que seja discutida no meio acadêmico. Além da necessidade de investimentos na formação continuada dos professores da sala regular na área da educação especial/inclusiva (ABDALLA, 2016; BEZERRA, 2016).

Além de compreenderem a necessidade da formação continuada para os professores, os autores também apontaram o trabalho colaborativo como importante caminho no processo de inclusão escolar. De acordo com as pesquisas de Magalhães e Acioli (2020), Mascena (2020), Marques e Giroto (2016), Batista e Manzoli (2016), o apoio da equipe escolar é fundamental para práticas educativas inclusivas, pois permite que os professores possam aprender, trocar experiências e construírem juntos estratégias significativas de aprendizagens. Como aborda a pesquisa de Magalhães e Acioli (2020, p. 26):

Quando se é trabalhado em conjunto é nítido que propõem a criança melhores oportunidades na evolução de suas capacidades $[\ldots]$, a escola deve [...] disponibilizar para o professor materiais didáticos diversificados, materiais lúdicos, recursos audiovisuais, espaço físico adequado para se trabalhar com a criança, entre outros recursos que podem enriquecer a qualidade do ensino e a inclusão [...] na educação infantil.

Além do mais, a equipe escolar deve estar envolvida no processo de inclusão, providenciando momentos em que haja um trabalho colaborativo em 
prol desse processo, bem como apoiar o planejamento coletivo, principalmente, entre os professores da sala regular e da educação especial com parceria da família e dos outros profissionais envolvidos.

A pesquisa de Mendes e Galvani (2017) especifica ainda mais a perspectiva colaborativa, quando aborda práticas pedagógicas inclusivas baseadas neste segmento, que se configura a partir do trabalho em conjunto entre os professores do ensino comum e da educação especial. Como esclarecem Marin e Braun (2013, p. 53):

[...] o ensino colaborativo é uma alternativa de trabalho que envolve a cooperação entre um professor do ensino comum e um do ensino especial, os quais atuam juntos na mesma classe, quando há a presença de um ou mais alunos com necessidades educacionais especiais que demandam atenção diferenciada.

Mendes e Galvani (2017, p. 46) concluem, que o ensino colaborativo se revela uma estratégia que favorece significativamente o processo de inclusão, "em uma época em que, cada vez mais, as crianças com deficiência estão em processo de escolarização na educação infantil, o acesso e a apropriação das atividades pedagógicas ainda é um entrave no cotidiano escolar". No entanto, as autoras ressaltam a necessidade de uma legislação que regulamente o funcionamento do ensino colaborativo, bem como a ampliação desse serviço para outros locais. Também afirmam a importância da continuidade e da permanência do trabalho, pois é notório que o trabalho temporário realizado pelos profissionais da educação especial na sala regular, acaba rompendo com o ensino colaborativo e consequentemente compromete a eficácia no processo de inclusão das crianças PAEE.

A partir da análise da pesquisa de Mendes e Galvani (2017), percebe-se o quanto essa proposta de ensino é viável, pois na maioria dos casos, é observado o trabalho individualizado realizado pelo docente na sala regular, uma vez que este, não consegue, na maioria das vezes, encontrar apoio especializado e nem suporte da instituição de ensino. Dessa maneira, o processo de escolarização do aluno PAEE tem uma grande probabilidade de ser comprometido, pois como enfatiza Marin e Braun (2013, p. 58) "dificilmente, um único docente será capaz de buscar respostas educativas e organizar adequadamente o trabalho pedagógico".

Diante do exposto, pode-se perceber o quão possível e necessário é a inclusão na educação infantil, visto que todas as crianças PAEE terão as mesmas oportunidades de vivenciarem experiências, de se desenvolverem e aprenderem como as outras crianças da sua idade. O convívio entre as crianças na educação infantil é benefício para todas, em razão de que possibilita o desenvolvimento de valores, como o respeito mútuo, valorização da diversidade e potencialidades de cada um. No entanto, as pesquisas evidenciam a necessidade de formação continuada, recursos humanos e materiais aos professores do ensino regular com ênfase no trabalho colaborativo. 


\section{Considerações finais}

A acessibilidade curricular vem sendo cenário de intensas discussões no decorrer dos anos, posto que, a grande preocupação é de como proporcionar a aprendizagem a todos os alunos, principalmente, os alunos PAEE. Como já foi exposto, considera-se necessário e urgente que as propostas curriculares priorizem a diversidade, garantindo escola, currículo e aprendizagem de qualidade a todos os cidadãos.

Verifica-se que o professor tem papel fundamental no processo de inclusão escolar, tendo em vista que este tem um contato mais próximo e direto com o aluno PAEE na sala regular. Dessa maneira, observa-se a dificuldade que os docentes têm no desenvolvimento de estratégias pedagógicas diversificadas considerando as especificidades e as possibilidades que os alunos apresentam.

Nessa perspectiva, percebeu-se no decorrer das pesquisas e das análises dos autores, que os professores participantes possuem concepções e atitudes favoráveis à inclusão, compreendendo que é direito de todos à educação. Também é importante apontar que apesar da insegurança pela falta de formação continuada e de apoio a equipe escolar, os professores precisam utilizar estratégias curriculares diversificadas para atender as especificidades de cada aluno.

O estudo possibilitou perceber a necessidade da escola implantar em suas metas e objetivos educacionais a proposta de inclusão que contemple não apenas o direito à matricula e à participação nas relações sociais, mas também na formação da educação especial e da sala regular com ênfase em práticas pedagógicas diversificadas. Observou também o trabalho em equipe com a comunidade escolar, e finalmente, o planejamento e o trabalho colaborativo que favoreçam o compartilhamento de ideias, experiências, sugestões, criação de recursos e materiais que atendam as especificidades desse alunado.

Diante do exposto, percebe-se a partir das discussões e reflexões levantadas pelos autores nas pesquisas, o empenho dos professores das salas regulares em incluírem as crianças PAEE nas salas regulares. Entretanto, é necessário que haja um trabalho de colaboração na comunidade escolar com valorização do planejamento pedagógico, formação continuada para os professores e, como sugerido em uma das pesquisas que apresentou resultados exitosos, a presença do professor da educação especial atuando junto com o professor regente da sala regular, no intuito de superar as dificuldades encontradas pelos alunos PAEE.

É inegável a necessidade de que sejam realizados mais estudos sobre questões relacionadas às práticas pedagógicas voltadas para a inclusão de crianças PAEE na educação infantil, com o objetivo de erradicar ou minimizar as dificuldades encontradas no processo de desenvolvimento e aprendizagem desse alunado no ambiente escolar. 


\section{REFERÊNCIAS}

ABDALLA, Ana Paula. Representações de professores sobre a inclusão escolar. 2016. Dissertação (Mestrado em Educação) - Universidade Estadual Paulista, Faculdade de Filosofia e Ciências, 2016.

ALVES, Fabíola Fernanda Patrocínio. A inclusão das crianças com deficiência na educação infantil: processo em construção. Revista Educação, v. 41, n. 2, p. 270-279, mai. /ago. 2018. Disponível em: https://revistaseletronicas.pucrs.br/ojs/index.php/faced/article/view/26786/17 263 Acesso em: 20 jan. 2021.

BAPTISTA, Claudio Roberto. Ação Pedagógica e Educação Especial: para além do AEE. In: JESUS, Denise Meyreles de; BAPTISTA, Claudio Roberto; CAIADO, Katia Regina Moreno. Prática pedagógica na educação: multiplicidade do atendimento educacional especializado. Araraquara: Junqueira \& Marins Editores; Brasília. 2013, p. 43 - 61.

BATISTA, Bruna Rafaela de; MANZOLI, Luci Pastor. Educação inclusiva: um estudo de caso sobre o trabalho docente na educação infantil. Revista IberoAmericana de Estudos em Educação, v. 11, n. esp. 2, p. 881-894, 2016. Disponível em:

https://periodicos.fclar.unesp.br/iberoamericana/article/view/8932/5874 Acesso em: 15 jan. 2021.

BEZERRA, Giovani Ferreira. Preparando a primavera: contribuições preliminares para uma crítica superadora à pedagogia da inclusão. Revista Histedbr On-line, Campinas, n. 68, p. 272-287, jun. 2016. Disponível em: https://periodicos.sbu.unicamp.br/ojs/index.php/histedbr/article/view/864649 9 Acesso em: 15 jan. 2021.

BRASIL. Constituição da República Federativa do Brasil. Brasília, DF, 1988. Disponível em:

http://www.planalto.gov.br/ccivil_03/Constituicao/Constituicao.htm Acesso em: 5 jan. 2021.

BRASIL. Estatuto da Criança e do Adolescente. Brasília, 1990. Disponível em: http://www.planalto.gov.br/ccivil_03/leis/L8069.htm Acesso em: 12 jan. 2021.

BRASIL. Estatuto da Pessoa com Deficiência. Brasília, 2015. Disponível em: http://www.planalto.gov.br/Ccivil_03/_Ato20152018/2015/Lei/L13146.htm Acesso: 15 jan. 2021.

BRASIL. Lei de Diretrizes e Bases da Educação. Brasília: MEC, 1996. Disponível em: http://www.planalto.gov.br/ccivil_03/Leis/L9394.htm Acesso em: 12 jan. 2021. 


\section{BRASIL. Política Nacional de Educação Especial na Perspectiva da} Educação Inclusiva. Brasília, MEC, 2008. Disponível em: http://portal.mec.gov.br/seesp/arquivos/pdf/politica.pdf Acesso em: 15 jan. 2021.

BRASIL. Resolução no 4, de 2 de outubro de 2009. Institui as Diretrizes Operacionais para o Atendimento Educacional Especializado na Educação Básica, na modalidade Educação Especial. Ministério da Educação. Conselho Nacional de Educação, Câmara de Educação Básica, Brasília, 2009. Disponível em: http://portal.mec.gov.br/dmdocuments/rceb004_09.pdf. Acesso: 20 jan. 2021.

DECLARAÇÃO DE SALAMANCA: Sobre princípios, políticas e práticas na área das necessidades educativas especiais. Salamanca - Espanha, 1994. Disponível em: http://portal.mec.gov.br/seesp/arquivos/pdf/salamanca.pdf Acesso em: 20 jan.2021.

FACHINETTI, Tamiris Aparecida; NASCIMENTO, Beatriz Aparecida Barboza do; GIROTO, Claudia Regina Mosca. 0 trabalho pedagógico para alunos público-alvo da educação especial: investigando a inclusão na educação infantil. Revista Ibero-Americana de Estudos em Educação, v. 11, n. esp. 2, p. 861-880, 2016. Disponível em:

https://periodicos.fclar.unesp.br/iberoamericana/article/view/8931 Acesso em: 15 jan. 2021.

GIL, Antônio Carlos. Como elaborar projetos de pesquisa. São Paulo: Atlas, 2002.

HEREDERO, Eladio Sebastian. A escola inclusiva e estratégias para fazer frente a ela: as adaptações curriculares. Revista Acta Scientiarum Education, Maringá, v. 32, n. 2, p. 193-208, 2010. Disponível em:

https://periodicos.uem.br/ojs/index.php/ActaSciEduc/article/view/9772 Acesso em: 15 jan. 2021.

JOMTIEN. Declaração mundial sobre educação para todos. Unesco, 1990. Disponível em:

http://unesdoc.unesco.org/images/0008/000862/086291por.pdf Acesso em: 20 jan. 2021.

MAGALHÃES, Milena Silva; ACIOLI, Adenize Costa. $\mathbf{O}$ professor e a inclusão de crianças com Transtorno do Espectro autista - TEA nas salas de educação. Revista Educação e (Trans)formação, Arapiraca - AL, dez. 2020. Disponível em:

http://www.journals.ufrpe.br/index.php/educacaoetransformacao/article/view/ 3024 Acesso em: 15 jan. 2021. 
MARIN, Márcia; BRAUN, Patrícia. Ensino colaborativo como prática de inclusão escolar. In: GLAT, Rosana; PLETSH, Márcia Denise. Estratégias educacionais diferenciadas para alunos com necessidades Especiais. Rio de Janeiro: EdUERJ, 2013.

MARQUES, Jaqueline Belga; GIROTO, Claudia Regina Mosca. Trabalho docente com alunos público-alvo da educação especial na educação infantil. Revista Ibero-Americana de Estudos em Educação, v.11, n. esp. 2, p. 895-910, 2016. Disponível em:

https://periodicos.fclar.unesp.br/iberoamericana/article/view/8933 Acesso em: 10 jan. 2021.

MASCENA, Cinthya Campos de Oliveira. Educação especial para crianças de zero a três anos: perspectivas e práticas de profissionais da educação infantil. Revista Educação Especial em Debate, v. 5, n. 9, p. 110-130, jan. /jun. 2020. Disponível em: http://periodicos.ufes.br/reed Acesso em: 10 jan. 2021.

MELO, Josefa Gomes dos Santos; COUTINHO, Diogenes José Gusmão. Educação infantil: Métodos e estratégias para inclusão. Revista Espacios. v. 41, n. 18, p. 4, 2020. Disponível em: https://www.revistaespacios.com/a20v41n18/a20v41n18p04.pdf Acesso em: 15 jan. 2021.

MENDES, Enicéia Gonçalves. Inclusão marco zero: começando pelas creches. Araraquara: Junqueira \& Marin Editores; Brasília, 2010.

MENDES, Enicéia Gonçalves. Sobre alunos "incluídos" ou "da inclusão": reflexões sobre o conceito de inclusão escolar. In: VICTOR, Sonia Lopes; VIEIRA, Alexandro Braga; OLIVEIRA, Ivone Martins de. Educação especial inclusiva: conceituações, medicalização e políticas - Campos dos Goytacazes, RJ: Brasil Multicultural, 2017.

MENDES, Melina Thaís da Silva; GALVANI, Márcia Duarte. O ensino colaborativo como facilitador da educação inclusiva na educação infantil. Revista Diálogos e Perspectivas em Educação Especial, v. 4, n. 1, p. 45-60, 2017. Disponível em:

https://revistas.marilia.unesp.br/index.php/dialogoseperspectivas/article/view/ 7329 Acesso em: 10 jan. 2021.

PLETSCH, Márcia Denise; GLAT, Rosana. Plano Educacional Individualizado (PEI): um diálogo entre práticas curriculares e processos de avaliação escolar. In: GLAT, Rosana; PLETSCH, Marcia Denise (Org.). Estratégias educacionais diferenciadas para alunos com necessidades especiais. Rio de Janeiro: EdUERJ, 2013, p. 17-32. 
SANTIAGO, Mylene Cristina; SANTOS, Mônica Pereira dos. Planejamento de estratégias para o processo de inclusão: desafios em questão. Revista Educação e Realidade, v. 40, n. 2, p. 485-502, 2015. Disponível em: https://www.redalyc.org/pdf/3172/317238458009.pdf Acesso: 05 mar. 2021.

SANTOS; Cristiane Sousa; ALMEIDA, Yara de Souza. Inclusão na educação infantil: desafios e possibilidades através das práticas pedagógicas. RPGERevista de Política e Gestão Educacional, v. 21, n. 3, p. 1423-1432, set. /dez. 2017. Disponível em:

https://periodicos.fclar.unesp.br/rpge/article/view/10170/7099 Acesso em: 15 jan. 2021.

SOMOS EDUCAÇÃO. Raio-x da educação inclusiva no Brasil: um panorama da educação especial sob a perspectiva da inclusão no país, 2020. Disponível em: https://www.somoseducacao.com.br/conteudos-paradownload/categoria/e-book/ Acesso: 05 jan. 2021.

SOUSA, Antonia Josiane de; SILVA, Jáderson Cavalcante da; LIMA, Nágila Rabelo. Educação especial dos surdos: o que dizem os docentes em uma escola de educação infantil no Município de Itapipoca/CE. Revista do Plano Nacional de Formação de Professores da Educação Básica, v. 7, n. 2, p. 23-38, jul. /dez. 2019. Disponível em:

https://revistas.ufpi.br/index.php/parfor/article/view/9746 Acesso em: 15 jan. 2021.

SOUZA, Maewa Martina Gomes da Silva; PEREIRA, Adriana Alonso; LINDOLPHO, David Marcos Perrenoud. Mudanças de atitudes sociais de professores em relação à inclusão de alunos com deficiência. In: PAPIM, Angelo Antonio Puzipe; ARAUJO, Mariane Andreuzzi de; PAIXÃO, Kátia de Moura Graça; SILVA, Glacielma de Fátima da (Orgs.). Inclusão Escolar: perspectivas e práticas pedagógicas contemporâneas - Porto Alegre, RS: Editora Fi, 2018.

VAGULA, Edilaine. O Planejamento como elemento articulador da prática pedagógica. In: OLIVEIRA, Diene Eire de Mello Bortotti de; SANTOS, Adriana Reina de Jesus; REZENDE, Aparecida de. Formação de professores e ensino aspectos teóricos metodológicos. Londrina: UEL, 2011.

VILARONGA, Carla Ariela Rios. MENDES Enicéia Gonçalves. Ensino colaborativo para o apoio à inclusão escolar: práticas colaborativas entre os professores. Rev. Bras. Estud. Pedagog. , Brasília, v. 95, n. 239, p. 139151, jan./abr. 2014. Disponível em:

https://www.scielo.br/pdf/rbeped/v95n239/a08v95n239.pdf Acesso em: 15 fev. 2021.

VÍLCHEZ Iván Carlos Curioso. Uma escola em transformação: reflexões essenciais de uma educação inclusiva para estudantes com deficiência. In: 
PAPIM, Angelo Antonio Puzipe; ARAUJO, Mariane Andreuzzi de; PAIXÃO, Kátia de Moura Graça; SILVA, Glacielma de Fátima da (Orgs.). Inclusão Escolar: perspectivas e práticas pedagógicas contemporâneas - Porto Alegre, RS:

Editora $\mathrm{Fi}, 2018$.

Recebido em: 13 de julho de 2021. Aceito em: 14 de setembro de 2021. Publicado em: 05 de janeiro de 2022. 